\title{
Streptococcus merionis sp. nov., isolated from Mongolian jirds (Meriones unguiculatus)
}

\author{
Correspondence \\ Ulrich Vogel \\ uvogel@hygiene. \\ uni-wuerzburg.de
}

\author{
Dennis Tappe, ${ }^{1}$ Rüdiger Pukall, ${ }^{2}$ Peter Schumann, ${ }^{2}$ Sabine Gronow, ${ }^{2}$ \\ Markus Spiliotis, ${ }^{1}$ Heike Claus, ${ }^{1}$ Klaus Brehm ${ }^{1}$ and Ulrich Vogel ${ }^{1}$ \\ ${ }^{1}$ Institute of Hygiene and Microbiology, University of Würzburg, Josef-Schneider-Straße 2, \\ D-97080 Würzburg, Germany \\ ${ }^{2} \mathrm{DSMZ}$ - Deutsche Sammlung von Mikroorganismen und Zellkulturen GmbH, Inhoffenstraße 7b, \\ D-38124 Braunschweig, Germany
}

\begin{abstract}
Gram-positive, catalase-negative, chain-forming, coccus-shaped organisms were isolated both from intraperitoneally grown vesicles of the fox tapeworm Echinococcus multilocularis and the oropharynges of laboratory-kept Mongolian jirds (Meriones unguiculatus). The strains displayed no haemolytic activity on Columbia sheep blood agar, pyrrolidonyl arylamidase activity was negative and the organisms reacted weakly with Lancefield group D antiserum. On the basis of phenotypic characteristics, the strains were tentatively identified as members of the genus Streptococcus. Comparative 16S rRNA gene sequencing studies confirmed their assignment to the genus Streptococcus and revealed that Streptococcus hyointestinalis DSM $20770^{\top}$ was their closest phylogenetic neighbour ( $96.5 \%$ sequence similarity). The levels of $16 \mathrm{~S}$ rRNA gene sequence similarity between the isolates and representatives of species of the genus Streptococcus were only 95.7-96.2\%. On the basis of the phenotypic and molecular data presented, the isolates from Mongolian jirds represent a novel species of the genus Streptococcus, for which the name Streptococcus merionis sp. nov. is proposed. The type strain is WUE3771 ${ }^{\top}\left(=\mathrm{DSM} 19192^{\top}=\right.$ CCUG $\left.54871^{\top}\right)$.
\end{abstract}

The genus Streptococcus encompasses a large group of Gram-positive, coccus-shaped, chain-forming, catalasenegative organisms with a low $\mathrm{G}+\mathrm{C}$ content. Improved phenotypic and molecular identification methods have driven the description of a multitude of novel streptococcal species from human and animal sources in recent years (Facklam, 2002). It is expected that further diversity will be discovered for this genus, particularly from animal sources (e.g. Lawson et al., 2005). During in vitro culture studies with the larval stage of the fox tapeworm Echinococcus multilocularis in the presence of ciprofloxacin (Spiliotis et al., 2004; Brehm et al., 2006), parasite vesicles initially harvested from the peritoneal cavities of laboratory-kept Mongolian jirds (Meriones unguiculatus) were discovered to harbour Gram-positive Streptococcus-like organisms inside the vesicle cavity. An identical strain was subse-

Abbreviation: MALDI-TOF MS, matrix-assisted laser desorption/ionization time-of-flight mass spectrometry.

The GenBank/EMBL/DDBJ accession number for the 16S rRNA gene sequence of strain WUE3771 ${ }^{\top}$ is AM396401.

Supplementary figures showing a maximum-likelihood phylogenetic tree (based on 16S rRNA gene sequences) and a score-oriented dendrogram (based on data from MALDI-TOF MS) for the novel strains and related species in the genus Streptococcus are available with the online version of this paper. quently isolated from oropharyngeal swabs taken from the rodent hosts.

The streptococcal strain $\mathrm{WUE} 3771^{\mathrm{T}}$ was grown on Columbia sheep blood agar (bioMérieux) at $37{ }^{\circ} \mathrm{C}$ under aerobic conditions in a $5 \% \mathrm{CO}_{2}$-enriched atmosphere, on Schaedler blood agar (Becton Dickinson) under anaerobic conditions, and in liquid culture using brain-heart infusion medium (Becton Dickinson). Reisolation of the bacterial strains from the oral microflora of $M$. unguiculatus was performed using Luria-Bertani agar (Becton Dickinson) supplemented with $2 \mu \mathrm{g}$ ciprofloxacin $\mathrm{ml}^{-1}$.

Strain WUE3771 ${ }^{\mathrm{T}}$ was analysed biochemically using the API 20 Strep, Rapid ID32 Strep, API 20E and API Coryne test systems (bioMérieux). Lancefield serological grouping was determined by using the Streptex test system (Remel). The Ciprofloxacin Etest (AB Biodisk) was employed.

For chemotaxonomic analysis, strain WUE3771 ${ }^{\mathrm{T}}$ was grown in BBL tryptic soy broth supplemented with yeast extract $\left(3 \mathrm{~g} \mathrm{l}^{-1}\right)$ and incubated under microaerophilic conditions at $37{ }^{\circ} \mathrm{C}$. Biomass was harvested by centrifugation. Analysis of the peptidoglycan structure was carried out as described by Schleifer (1985) and Schleifer \& Kandler (1972), with the modification that TLC on cellulose was used instead of paper chromatography. 
For initial 16S rRNA gene sequence analysis of the Grampositive cocci isolated from the E. multilocularis vesicles, a partial 16S rRNA gene was amplified using the universal primers BAK11w (5'-AGTTTGATCHTGGCTCAG-3') and PC3mod (5'-GGACTACHAGGGTATCTAAT-3') [Goldenberger et al., 1997; note that the $\mathrm{H}(\mathrm{A} / \mathrm{C} / \mathrm{T})$ at position 10 of BAK $11 \mathrm{w}$ originally was published as an $\mathrm{M}(\mathrm{A} / \mathrm{C})]$. The PCR conditions were as follows: initial denaturation at $95{ }^{\circ} \mathrm{C}$ for $10 \mathrm{~min}$; 30 cycles of annealing for $90 \mathrm{~s}$ at $55{ }^{\circ} \mathrm{C}$, extension at $72{ }^{\circ} \mathrm{C}$ for $90 \mathrm{~s}$ and denaturation at $94{ }^{\circ} \mathrm{C}$ for $30 \mathrm{~s}$; final extension at $72{ }^{\circ} \mathrm{C}$ for $20 \mathrm{~min}$. A $50 \mu \mathrm{l}$ PCR contained $0.4 \mu \mathrm{l} \quad(2 \mathrm{U}) \quad$ AmpliTaq Gold (Applied Biosystems), $1 \mu \mathrm{l}$ each of the primer solutions $(10 \mu \mathrm{M})$, $3 \mu \mathrm{l} \mathrm{MgCl}_{2}(25 \mathrm{mM}), 1 \mu \mathrm{l}$ dNTP $(2.5 \mathrm{mM}$ each dNTP; PeqLab Biotechnologie), $5 \mu 110 \times$ PCR buffer II (Applied Biosystems) and $5 \mu \mathrm{l}$ boiled bacterial suspension.

Gene cloning was used to produce an almost-complete $16 \mathrm{~S}$ rRNA gene sequence. A digoxigenin-labelled $16 \mathrm{~S}$ rRNA probe was generated from the approximately $800 \mathrm{bp}$ PCR product of primers BAK11w and PC 3 mod. The probe was hybridized to HindIII-digested chromosomal DNA of the novel strain. Using standard cloning procedures, a $2.8 \mathrm{~kb}$ fragment was cloned, resulting in plasmid pIK2. A partial $16 \mathrm{~S}$ rRNA gene sequence (1354 bp) was determined by means of primer walking.

The partial 16S rRNA gene sequence of strain WUE $3771^{\mathrm{T}}$, comprising $1354 \mathrm{bp}$, was aligned manually according to the secondary structure of the $16 \mathrm{~S}$ rRNA molecule and compared with published sequences from the 16S rRNA gene sequence database of the DSMZ, including sequences available from the Ribosomal Database Project (Maidak et al., 2001) and GenBank/EMBL. A manual alignment was constructed with the BioEdit program (Hall, 1999). Similarities were converted into genetic distances that compensate for multiple substitutions at any given site in the sequence (Jukes \& Cantor, 1969). The neighbourjoining method contained within the PHYLIP package was used for construction of the phylogenetic dendrogram, while maximum-likelihood analysis was performed using the program DNAML (Felsenstein, 1993). In addition, the web-based program EzTaxon (Chun et al., 2007) was used for pairwise comparison of sequences in order to obtain sequence-similarity values.

Matrix-assisted laser desorption/ionization time-of-flight mass spectrometry (MALDI-TOF MS) was conducted by using a Microflex L20 mass spectrometer (Bruker Daltonics) equipped with an $\mathrm{N}_{2}$ laser. All spectra were recorded in linear, positive-ion mode. The acceleration voltage was $20 \mathrm{kV}$. A mass range of $2000-20000 \mathrm{~m} / z$ was used for the analysis. Sample preparation was done as described by Schumann (2007). Spectra obtained by using MALDI-TOF MS were compared by using the BioTyper (version 1.1; Bruker Daltronics) software package.

Cells of strain WUE $3771^{\mathrm{T}}$ were Gram-positive and coccusshaped and formed chains. In DSMZ medium $92(3 \%$ trypticase soy broth, $0.3 \%$ yeast extract), the strain grew well at $37{ }^{\circ} \mathrm{C}$, but displayed reduced growth at $45{ }^{\circ} \mathrm{C}$. The bacteria did not grow at $10{ }^{\circ} \mathrm{C}$ or in the presence of $6.5 \%$ $\mathrm{NaCl}$ during a 7 day observation period. Spore formation was not observed. Motility could not be demonstrated on semi-solid agar. Strain WUE $3771^{\mathrm{T}}$ was found to be facultatively anaerobic, catalase-negative and oxidasenegative. Pyrrolidonyl arylamidase activity was absent and the bacteria reacted weakly with Lancefield group D antiserum in the Streptex test. In the API 20 Strep test system, the strain exhibited the profile 6451471, which did not correspond to any known streptococcal species. In the API Rapid ID 32 Strep test system, the strain was characterized by the profile 73076251150 . In the various API test kits, acid was produced from lactose, trehalose, inulin, raffinose, starch, maltose, pullulan and methyl $\beta$-Dglucopyranoside. Acid was not produced from D-ribose, Larabinose, D-mannitol, D-sorbitol, glycogen, D-xylose, inositol, D-rhamnose, melibiose or amygdalin. The bacteria hydrolysed aesculin and hippurate, but not gelatin. The Voges-Proskauer reaction was negative. Leucine aminopeptidase, arginine dihydrolase, $\beta$-glucuronidase, $\beta$-galactosidase, $\beta$-glucosidase, $\beta$-mannosidase and alaninephenylalanine-proline arylamidase activities were detected. $\alpha$-Galactosidase and alkaline phosphatase activities were absent. The minimum inhibitory concentration of ciprofloxacin was $2.0 \mu \mathrm{g} \mathrm{ml}^{-1}$. Characteristics of strain WUE3771 $1^{\mathrm{T}}$ are summarized in Table 1.

A BLAST search of GenBank revealed that the highest sequence similarities for the almost-complete (1354 bp) 16S rRNA gene sequence of strain WUE3771 ${ }^{\mathrm{T}}$ were found to Streptococcus hyointestinalis DSM $20770^{\mathrm{T}}(96.5 \%)$. Further analysis with the EzTaxon software (Chun et al., 2007) confirmed the affiliation of strain WUE $3771^{\mathrm{T}}$ to the genus Streptococcus and revealed S. hyointestinalis to be its closest phylogenetic neighbour. The levels of 16S rRNA gene sequence similarity between the isolate and representatives of species of the genus Streptococcus were in the range $95.7-96.2 \%$. This was the first indication that strain WUE3771 ${ }^{\mathrm{T}}$ represents a novel species of the genus Streptococcus.

The type of peptidoglycan present in strain WUE $3771^{\mathrm{T}}$ was A3 $\alpha$ L-Lys-L-Thr-L-Ser(L-Ala) (type A11.29, according to the 2004 DSMZ Catalogue of Strains; available at http:// www.dsmz.de/microorganisms/main.php?content_id=35), differing in this respect from its closest phylogenetic neighbour, S. hyointestinalis, for which an A3 $\alpha$ peptidoglycan lacking threonine was reported (Devriese et al., 1988).

According to Facklam (2002), non- $\beta$-haemolytic, Grampositive cocci occurring in chains have been placed in the Streptococcus bovis-Streptococcus equinus group (S. bovis, S. equinus, Streptococcus infantarius subsp. infantarius, Streptococcus lutetiensis, Streptococcus gallolyticus subsp. gallolyticus, S. gallolyticus subsp. macedonicus, S. gallolyticus subsp. pasteurianus, Streptococcus alactolyticus and Streptococcus henryi) reacting with Lancefield group D antigen. Furthermore, the viridans streptococci (including 
Table 1. Characteristics useful for distinguishing Streptococcus merionis sp. nov. from phylogenetically related streptococci

Strains: 1, S. merionis DSM 19192 ${ }^{\mathrm{T}}$, DSM 19912, DSM 19913 and DSM 19914; 2, S. hyointestinalis DSM 20770 ${ }^{\mathrm{T}}$; 3, S. gallinaceus DSM 15349 ${ }^{\mathrm{T}}$; 4, S. minor DSM $17118^{\mathrm{T}}$; 5, S. alactolyticus DSM $20728^{\mathrm{T}}$; 6, S. henryi DSM 19005 ${ }^{\mathrm{T}}$; 7, S. lutetiensis DSM 15350 ; 8, S. equinus DSM 20558 ${ }^{\mathrm{T}}$; 9, S. gallolyticus subsp. gallolyticus DSM $16831^{\mathrm{T}}$; 10, S. gallolyticus subsp. macedonicus DSM $15879^{\mathrm{T}}$. Data are from the present study. $(+)$ indicates a weak reaction.

\begin{tabular}{|c|c|c|c|c|c|c|c|c|c|c|}
\hline Characteristic & 1 & 2 & 3 & 4 & 5 & 6 & 7 & 8 & 9 & 10 \\
\hline Acetoin (Voges-Proskauer) & - & + & - & - & + & - & + & + & + & + \\
\hline Hippurate hydrolysis & + & - & - & - & - & - & - & - & - & - \\
\hline \multicolumn{11}{|l|}{ Production of: } \\
\hline$\alpha$-Galactosidase & - & + & + & + & + & + & + & - & + & + \\
\hline$\beta$-Galactosidase & + & - & + & - & - & + & - & - & - & - \\
\hline$\beta$-Glucosidase & + & + & + & + & + & + & - & + & + & - \\
\hline \multicolumn{11}{|l|}{ Acid from: } \\
\hline Melibiose & - & $(+)$ & + & - & + & - & - & - & + & - \\
\hline Mannitol & - & - & + & + & + & + & - & - & + & - \\
\hline Ribose & - & - & + & - & - & - & - & - & - & - \\
\hline Glycogen & - & - & - & + & - & + & - & - & + & - \\
\hline
\end{tabular}

S. hyointestinalis) are allocated to this group. Recently, $S$. hyointestinalis was thought to belong to the pyogenic group of streptococci, but this finding did not receive substantial support from results obtained by using RNase P $(r n p B)$ gene sequences for genotyping of the streptococci, as shown by Täpp et al. (2003). Strain WUE3771 ${ }^{\mathrm{T}}$ also displayed a weak reaction with Lancefield group D antiserum. As shown in Fig. 1, S. hyointestinalis DSM $20770^{\mathrm{T}}$ and strain WUE3771 ${ }^{\mathrm{T}}$ formed a separate cluster, showing $<97 \%$ nucleotide sequence similarity to the $16 \mathrm{~S}$ rRNA gene sequences of other species of the genus Streptococcus. Neighbour-joining analysis placed this cluster near Streptococcus gallinaceus CCUG $42692^{\mathrm{T}}$ and Streptococcus minor LMG $21734^{\mathrm{T}}$, but the bootstrap value calculated for the branching point was low, indicating the low statistical significance of the order in which they separate. Even if other methods for tree reconstruction were applied, e.g. maximum likelihood (see Supplementary Fig. S1, available in IJSEM Online), the sequences of both strains clustered together. Both dendrograms (i.e. neighbour-joining and maximum-likelihood analyses) showed similar groupings for closely related species, but differences occur at deeper levels of relationship. In general, the maximum-likelihood approach is more robust than the neighbour-joining method and, in this case, showed that strain WUE3771 ${ }^{\mathrm{T}}$ is phylogenetically related to the members of the S. bovis-S. equinus complex. However, the addition of novel sequences in the future might change the phylogenetic evidence.

Recently, it was demonstrated by Stackebrandt et al. (2005) that MALDI-TOF MS analysis of bacterial cells might have taxonomic significance, in that ribosomal proteins and certain housekeeping proteins may be responsible for the mass spectra obtained. A score-oriented dendrogram based on MALDI-TOF MS spectra for selected Streptococcus species is available as Supplementary Fig. S2 in IJSEM
Online. All four of the novel isolates tested [WUE3771 ${ }^{\mathrm{T}}$ $\left(=\right.$ DSM 19192 $\left.{ }^{\mathrm{T}}\right)$, DSM 19912, DSM 19913 and DSM 19914] have the same spectrum, clustering next to $S$. gallinaceus DSM $15349^{\mathrm{T}}$, whereas S. hyointestinalis DSM $20770^{\mathrm{T}}$ falls within the $S$. equinus complex. Even though it has been shown that MALDI-TOF MS can be used for rapid and accurate identification of viridans streptococci (Friedrichs et al., 2007), this form of analysis was unable to support the phylogenetic positioning shown in the dendrograms.

To investigate the possible natural habitat of the novel organism, oral swabs were taken from 20 inbred Mongolian jirds, which were maintained in different cages at the animal-housing facility. From these swabs, 40 bacterial colonies were isolated, which grew on medium supplemented with $2 \mu \mathrm{g}$ ciprofloxacin $\mathrm{ml}^{-1}$ (corresponding to the minimum inhibitory concentration). Three catalase-negative colonies isolated from two animals were positive in a PCR employing the specific primers DTWUE_F (5'-AAGAGGGTCTAACACATGTTAGG-3') and DTWUE_R (5'-AGCCTTTTACTTCAGACTTACGG$\left.3^{\prime}\right)$; partial $16 \mathrm{~S}$ rRNA gene sequencing revealed that the strains were identical to the type strain, WUE $3771^{\mathrm{T}}$. This finding suggests that WUE $3771^{\mathrm{T}}$ inhabited the oral cavities of gerbils held in the animal-housing facility. Dissemination to intraperitoneal E. multilocularis vesicles could have occurred during bacteraemia, possibly after oral micro-lesions had been induced as a result of feeding, nibbling and biting of the rodents. The data obtained by using MALDI-TOF MS supported the results from the $16 \mathrm{~S}$ rRNA gene sequence analysis and provided further proof that all four isolates belonged to the same phylotype. On the basis of the phenotypic and molecular data presented, the isolates from Mongolian jirds represent a novel species of the genus Streptococcus, for which the name Streptococcus merionis sp. nov. is proposed. 


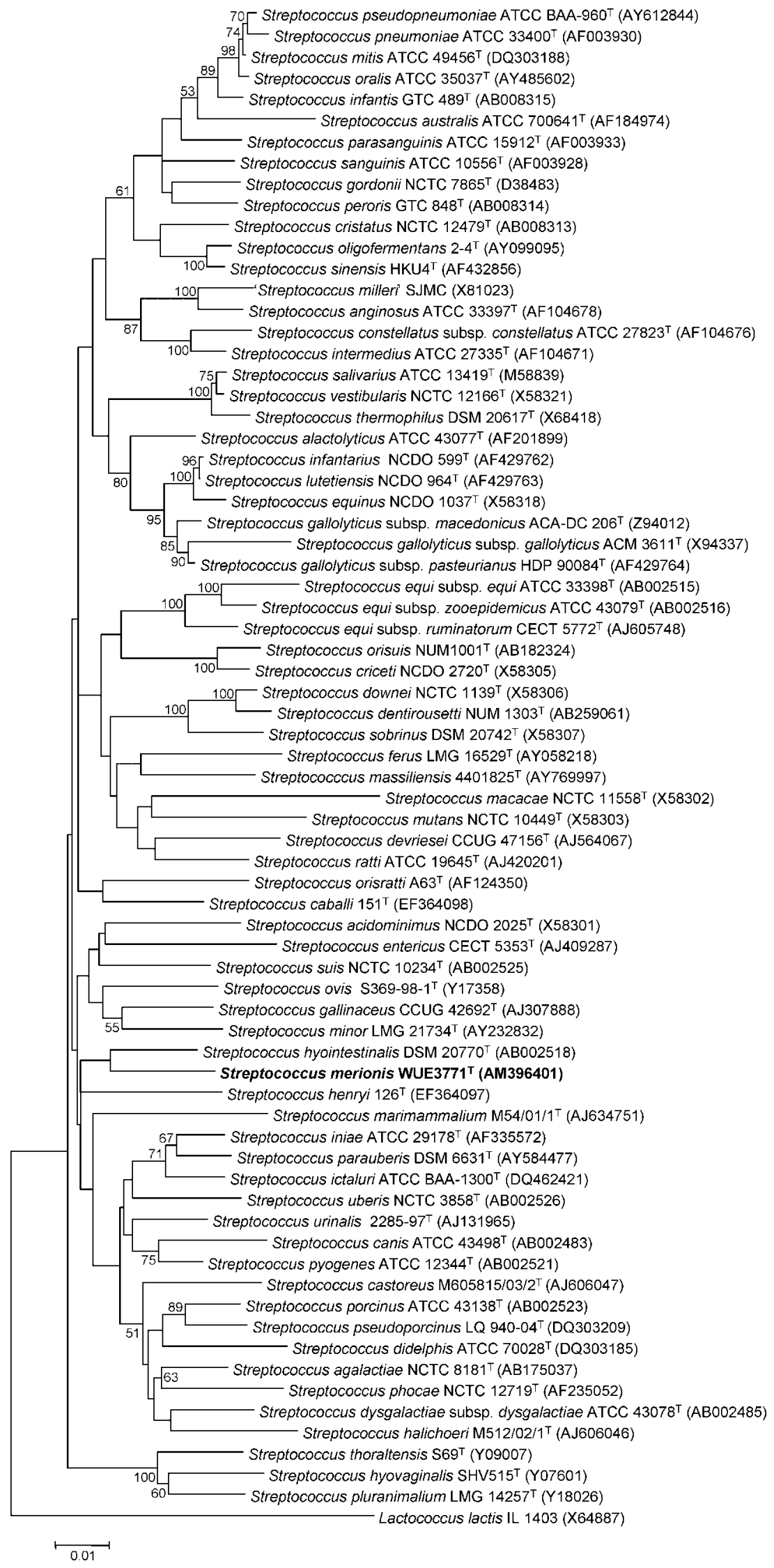

Fig. 1. Neighbour-joining phylogenetic tree based on 16S rRNA gene sequences, showing the relationships among strain WUE3771 ${ }^{\top}$ and related species of the genus Streptococcus. Bootstrap percentages (based on 1000 replications) $>50 \%$ are shown at branching points. Published sequences used were from the $16 \mathrm{~S}$ rRNA gene sequence database of the DSMZ, including sequences available from the Ribosomal Database Project (Maidak et al., 2001) and GenBank/EMBL. Bar, 1 substitution per 100 nucleotide positions. 


\section{Description of Streptococcus merionis sp. nov.}

Streptococcus merionis (me.ri.o' nis. N.L. gen. n. merionis of Meriones, the Mongolian jird, from which the bacterium was isolated).

Cells are Gram-positive cocci that occur in long chains when cultured in liquid media, such as brain-heart infusion broth. Grows well on both Columbia sheep blood agar and chocolate agar at $37{ }^{\circ} \mathrm{C}$ in a $5 \% \mathrm{CO}_{2}$-enriched atmosphere. Growth at $45{ }^{\circ} \mathrm{C}$ is weak; growth does not occur at $10{ }^{\circ} \mathrm{C}$. Growth is inhibited by the addition of $6.5 \% \mathrm{NaCl}$. Weak growth occurs facultatively under anaerobic conditions. On Columbia sheep blood agar, colonies are grey, non-haemolytic and $0.7-1.0 \mathrm{~mm}$ in diameter after $24 \mathrm{~h}$ incubation. The type strain is nonmotile, catalase-negative and oxidase-negative. Spore formation does not occur. Negative for pyrrolidonyl arylamidase activity. Weak reaction occurs with Lancefield group D antiserum. In API test kits, acid is produced from lactose, trehalose, inulin, raffinose, starch, maltose, pullulan and methyl $\beta$-D-glucopyranoside, but not from D-ribose, L-arabinose, D-mannitol, D-sorbitol, glycogen, D-xylose, inositol, D-rhamnose, melibiose or amygdalin. Aesculin and hippurate are hydrolysed, but gelatin is not. Activity is detected for leucine aminopeptidase, arginine dihydrolase, $\beta$-glucuronidase, $\beta$-galactosidase, $\beta$ glucosidase, $\beta$-mannosidase and alanine-phenylalanineproline arylamidase. Negative for $\alpha$-galactosidase, alkaline phosphatase and urease. Voges-Proskauer reaction is negative. The peptidoglycan type is DSMZ type A11.29 [A3 $\alpha$, L-Lys-L-Thr-L-Ser(L-Ala)].

The type strain, WUE $3771^{\mathrm{T}}\left(=\mathrm{DSM} \quad 19192^{\mathrm{T}}=\mathrm{CCUG}\right.$ $54871^{\mathrm{T}}$ ), was isolated from the oropharynges of laboratory-kept Mongolian jirds (Meriones unguiculatus). Reference strains are WUE3937 (=DSM 19912), WUE3938 (=DSM 19913) and WUE3939 (=DSM 19914).

\section{Acknowledgements}

The authors thank Isabell Kaluza for expert technical assistance. Rainer Brandner and Robina Vogel are thanked for help with the analysis of oral microbiota from animals of the genus Meriones. The work was funded by Research Focus SFB 479 of the German Research Foundation, projects A10 (U.V.) and C10 (K.B.). Enevold Falsen (Culture Collection, University of Göteborg, Sweden) is gratefully acknowledged for help with strain deposition. We are indebted to the nomenclatural reviewer for invaluable suggestions.

\section{References}

Brehm, K., Spiliotis, M., Zavala-Gongora, R., Konrad, C. \& Frosch, M. (2006). The molecular mechanisms of larval cestode development: first steps into an unknown world. Parasitol Int 55, S15-S21.
Chun, J., Lee, J.-H., Jung, Y., Kim, M., Kim, S., Kim, B. K. \& Lim, Y. W. (2007). EzTaxon: a web-based tool for the identification of prokaryotes based on $16 \mathrm{~S}$ ribosomal RNA gene sequences. Int J Syst Evol Microbiol 57, 2259-2261.

Devriese, L. A., Kilpper-Bälz, R. \& Schleifer, K. H. (1988). Streptococcus hyointestinalis sp. nov. from the gut of swine. Int $J$ Syst Bacteriol 38, 440-441.

Facklam, R. (2002). What happened to the streptococci: overview of taxonomic and nomenclature changes. Clin Microbiol Rev 15, 613630.

Felsenstein, J. (1993). PHYLIP (phylogeny inference package) version 3.5.1. Distributed by the author. Department of Genome Sciences, University of Washington, Seattle, WA, USA.

Friedrichs, C., Rodloff, A. C., Chhatwal, G. S., Schellenberger, W. \& Eschrich, K. (2007). Rapid identification of viridans streptococci by mass spectrometric discrimination. J Clin Microbiol 45, 2392-2397.

Goldenberger, D., Künzli, A., Vogt, P., Zbinden, R. \& Altwegg, M. (1997). Molecular diagnosis of bacterial endocarditis by broad-range PCR amplification and direct sequencing. J Clin Microbiol 35, 27332739.

Hall, T. A. (1999). BioEdit: a user-friendly biological sequence alignment editor and analysis program for Windows 95/98/NT. Nucleic Acids Symp Ser 41, 95-98.

Jukes, T. H. \& Cantor, C. R. (1969). Evolution of protein molecules. In Mammalian Protein Metabolism, pp. 21-132. Edited by N. Munro. New York: Academic Press.

Lawson, P. A., Foster, G., Falsen, E., Markopoulos, S. J. \& Collins, M. D. (2005). Streptococcus castoreus sp. nov., isolated from a beaver (Castor fiber). Int J Syst Evol Microbiol 55, 843-846.

Maidak, B. L., Cole, J. R., Lilburn, T. G., Parker, C. T., Jr, Saxman, P. R., Farris, R. J., Garrity, G. M., Olsen, G. J., Schmidt, T. M. \& Tiedje, J. M. (2001). The RDP-II (Ribosomal Database Project). Nucleic Acids Res 29, 173-174.

Schleifer, K. H. (1985). Analysis of the chemical composition and primary structure of murein. Methods Microbiol 18, 123-156.

Schleifer, K. H. \& Kandler, O. (1972). Peptidoglycan types of bacterial cell walls and their taxonomic implications. Bacteriol Rev 36, 407-477.

Schumann, P. (2007). MALDI-TOF mass spectrometry versus RIBOPRINTING in the quality control of bacterial strains. In Proceedings of the 11th International Conference on Culture Collections, ICCC 11, Goslar, Germany. Edited by E. Stackebrandt, M. Wozniczka, V. Weihs \& J. Sikorski. Braunschweig: Deutsche Sammlung von Mikroorganismen und Zellkulturen GmbH/World Federation for Culture Collections.

Spiliotis, M., Tappe, D., Sesterhenn, L. \& Brehm, K. (2004). Longterm in vitro cultivation of Echinococcus multilocularis metacestodes under axenic conditions. Parasitol Res 92, 430-432.

Stackebrandt, E., Päuker, O. \& Erhard, M. (2005). Grouping myxococci (Corallococcus) strains by matrix-assisted laser desorption ionization time-of-flight (MALDI-TOF) mass spectrometry: comparison with gene sequence phylogenies. Curr Microbiol 50, 71-77.

Täpp, J., Thollesson, M. \& Herrmann, B. (2003). Phylogenetic relationships and genotyping of the genus Streptococcus by sequence determination of the RNase P RNA gene, rnpB. Int J Syst Evol Microbiol 53, 1861-1871. 